\title{
Light Pollution and Seabird Fledglings: Targeting Efforts in Rescue Programs
}

\author{
AIRAM RODRÍGUEZ, ${ }^{\mathbf{1 , 2}}$ Research Department, Phillip Island Nature Parks, P.O. Box 973922 Cowes, Victoria, Australia \\ JENNIFER MOFFETT, Department of Biology and Program in Environmental Studies, Middlebury College, 14 Old Chapel Road, Middlebury, VT \\ 05753, USA \\ ANNA REVOLTÓS, Research Department, Phillip Island Nature Parks, P.O. Box 973922 Cowes, Victoria, Australia \\ PAULA WASIAK, Research Department, Phillip Island Nature Parks, P.O. Box 973922 Cowes, Victoria, Australia \\ REBECCA R. MCINTOSH, Research Department, Phillip Island Nature Parks, P.O. Box 973922 Cowes, Victoria, Australia \\ DUNCAN R. SUTHERLAND (DD, Research Department, Phillip Island Nature Parks, P.O. Box 973922 Cowes, Victoria, Australia \\ LEANNE RENWICK, Research Department, Phillip Island Nature Parks, P.O. Box 973922 Cowes, Victoria, Australia \\ PETER DANN, Research Department, Phillip Island Nature Parks, P.O. Box 973922 Corves, Victoria, Australia \\ ANDRÉ CHIARADIA, Research Department, Phillip Island Nature Parks, P.O. Box 973922 Cowes, Victoria, Australia
}

\begin{abstract}
One of the most critical phases in the life of petrels (Procellariiformes) is at fledging when young birds pass from parental dependence on land to an independent life at sea. To mitigate mortality at this time, rescue programs are implemented near breeding sites around the world, especially for birds grounded by artificial lights. We evaluated the plumage and body condition of short-tailed shearwater (Ardenna tenuirostris) fledglings captured at colonies just before departure in comparison to fledglings washed up on beaches and to fledglings attracted by artificial light along roads. We measured abundance of down, body mass, and body condition index as the standardized residuals of a regression of body mass on size, and employed linear models to test differences on body mass and body condition between locations. Beachwashed birds were underweight and in poor condition, suggesting their future survival probabilities at sea were low. Birds rescued on roads as a consequence of light attraction had lower body weights and condition indices than fledglings captured at the colony. However, more than $50 \%$ of light-attracted birds had attained similar weights to those of adults, suggesting they have higher probabilities of survival than beach-washed birds. Water-logged birds being washed onto beaches is a natural process, but birds grounded by lighting along roads is an increasing anthropogenic threat that requires management. Thus, management and conservation efforts should be directed to protect birds in the colonies and reduce light-induced mortality, ideally through the strategic reduction of light sources and lateral light spillage. When resources for conservation are limited, rescue programs should focus on rescuing birds from roads rather than beachwashed birds, which have a lower probability of survival. (c) 2017 The Wildlife Society.
\end{abstract}

KEY WORDS artificial light, body condition, fledgling, grounding, mortality, road kill, stranding, wreck.

Seabirds are one of the most endangered groups of birds, with petrels (order Procellariiformes) having the highest proportion of threatened species (Croxall et al. 2012, Paleczny et al. 2015). The main threats at sea are caused by interactions with commercial fisheries (e.g., competition, bycatch) and with pollution (e.g., oil spills, marine debris ingestion, entanglement), whereas on land, introduced predators can decimate breeding colonies by preying upon eggs, nestlings, or adults (Croxall et al. 2012). Given the

Received: 5 October 2016; Accepted: 7 January 2017

${ }^{1}$ Current address: Department of Evolutionary Ecology, Estación Biológica de Doñana (CSIC), Américo Vespucio 23, 41092 Seville, Spain.

${ }^{2}$ E-mail: airamrguez@ebd.csic.es threatened conservation status of seabirds, any anthropogenic sources of mortality deserve to be quantified and understood before any remedial or mitigation actions can be implemented (Croxall et al. 2012).

One of the most critical phases in the life of petrels is at fledging because young birds move from a parent-dependent life on land to an independent life at sea (Brooke 2004). As in most oceanic birds, there is no parental care after fledging, so young petrels have to learn to fly, search for and capture food at sea, and maintain their plumage for waterproofing without parental assistance (Warham 1990). Thus, survival rates during the first weeks at sea are among the lowest along their entire lives (Warham 1996, Brooke 2004). Numerous dead and dying fledglings are washed onto beaches close to breeding colonies during the fledging period (Warham 1990). Although the reasons for this mortality are not 
entirely understood, it may be related to natural processes (i.e., weather condition, plumage condition, parasitism, starvation; Gibson and Sefton 1955, Stonehouse 1964, Work and Rameyer 1999). In this context, environmental organizations call for public collaboration to rescue beachwashed young birds along some coasts in the proximities of large breeding colonies, giving them a second chance. Given the urgency of conservation for some of these petrels and the limited resources available, it is important to determine the relative conservation value of rescuing beach-washed fledglings against other management actions.

On top of natural sources of mortality during fledging, the ubiquitous use of artificial light at night by rising human populations exposes fledgling petrels to an increasing threat. Fledglings of burrow-nesting petrels are attracted to artificial lights when they first leave their nests and fly toward the sea (reviewed in Rodríguez et al. 2017). This phenomenon affects $>50$ burrow-nesting petrel species worldwide, some critically endangered, and it can cause mass mortality episodes with thousands of birds affected in a single fledging season (Rodríguez et al. 2017). Light-induced landings can be fatal for birds when they collide with human structures such as buildings, electric wires and pylons, fences, and posts. Such impacts can kill or injure the birds resulting in broken limbs or internal damage. Even if not injured, grounded birds may be unable to take to the air again, making them vulnerable to predation by wild or domestic animals, collision with vehicles while they wander on roads or highways, and starvation or dehydration when they are unable to find their way to the sea (Rodríguez et al. 2012). As a consequence of the high mortality caused by light pollution, rescue campaigns are organized each fledging season across many islands around the world by local governments, environmental organizations, or the general public (Telfer et al. 1987, Ainley et al. 2001, Le Corre et al. 2002, Rodríguez and Rodríguez 2009, Rodríguez et al. 2014). Despite the number and frequency of these rescue campaigns, few studies have assessed the body condition of fledglings grounded by lights (Rodríguez et al. 2012, 2015a; Wilhelm et al. 2013). These studies have assessed body condition only in relation to date, without a comparison with unaffected birds (Rodríguez et al. 2012, 2015a; Wilhelm et al. 2013). Thus, we do not currently know if birds grounded by lights are a random sample of the total fledglings produced by the population.

Fat reserves accumulated during chick development are important after fledging in long-lived birds; the fledglings with good body condition have a higher probability of recruitment into the breeding population (Becker and Bradley 2007, Maness and Anderson 2013). Although a preliminary study failed to detect any relationship between chick body mass and recruitment of short-tailed shearwaters (Ardenna tenuirostris; Meathrel and Carey 2007), a positive relationship has been identified for other shearwater species populations including Manx's (Puffinus puffinus), sooty (Puffinus griseus), and Cory's (Calonectris borealis; Perrins et al. 1973, Sagar and Horning 1998, Mougin et al. 2000, Perrins 2014). Thus, evaluating the body condition of rescued birds as a predictor of survival at sea may be useful to assess the management and success of petrel rescue programs. This assessment could help to develop new actions or protocols in the rescue programs, and enable a triage approach for rescue patrols when resources are limited and effort may be ill-spent rescuing those birds that have limited likelihood of survival.

The short-tailed shearwater is listed as a species of Least Concern (according to International Union for Conservation of Nature [IUCN] Red List status) breeding in southeastern Australia with a breeding population of around 23 million individuals (Skira 1991). This species is strongly affected by light pollution and by mass mortality events at sea during the fledging period (Carey 2011, Acampora et al. 2014, Peter and Dooley 2014, Rodríguez et al. 2014). Given its abundance, we used the short-tailed shearwater as a model species to inform and improve the rescue programs for populations of endangered and rare petrel species affected by light pollution or washed onto beaches for which adequate sample sizes are hard to collect. We assessed the body condition and plumage development of short-tailed shearwater fledglings captured in the breeding colony concurrently with fledglings washed onto beaches and fledglings grounded on the roads after being attracted by light. We predicted that fledglings from roads would attain similar body condition and plumage development than colony birds, whereas beachwashed fledglings would be underweight and with their plumage covered by down (early plumage development). Furthermore, we assessed whether the probability of birds grounded by artificial light being rescued dead or alive was related to body condition and plumage development. We expected that birds in poor body condition and showing immature plumage would have higher probabilities of dying.

\section{STUDY AREA}

We conducted this study on Phillip Island, southeastern Australia (Fig. 1; $38^{\circ} 29^{\prime} ; 145^{\circ} 15^{\prime}$ ), located about $140 \mathrm{~km}$ south-southeast of Melbourne, Victoria (Fig. 1). Phillip Island is $26 \mathrm{~km}$ long and $9 \mathrm{~km}$ wide, with an area of about $100 \mathrm{~km}^{2}$, and $97 \mathrm{~km}$ of coastline. Relief is mostly flat, and its maximum altitude is about $112 \mathrm{~m}$ above sea level. The mean daily maximum temperature varies from $23.8^{\circ} \mathrm{C}$ (Feb) to $13.7^{\circ} \mathrm{C} \mathrm{(Jul)}$ and the mean annual rainfall is $782.3 \mathrm{~mm}$, with June being the wettest month. South-westerly winds are the prevailing winds. With regard to land use, around $60 \%$ of the island surface is farmland devoted to grazing of sheep and cattle. The resident population is approximately 10,000 people and up to 50,000 visitors at peak holiday periods. The main sources of light pollution on Phillip Island are street lights, vehicles on roads, and private properties, although the light pollution levels are relatively low (max. radiance values $=\sim 6 \mathrm{nW} / \mathrm{sr} \times \mathrm{cm}^{2}$; Rodríguez et al. 2014). Phillip Island is an Important Bird Area, supporting $>1 \%$ of the global populations of both short-tailed shearwaters and little penguins (Eudyptula minor; BirdLife International 2015). Approximately 542,300 short-tailed shearwater pairs were estimated to breed in 25 colonies on the island (Harris and Bode 1981), although current estimates are higher (D. R. Sutherland, Phillip Island Nature Parks, unpublished data). 


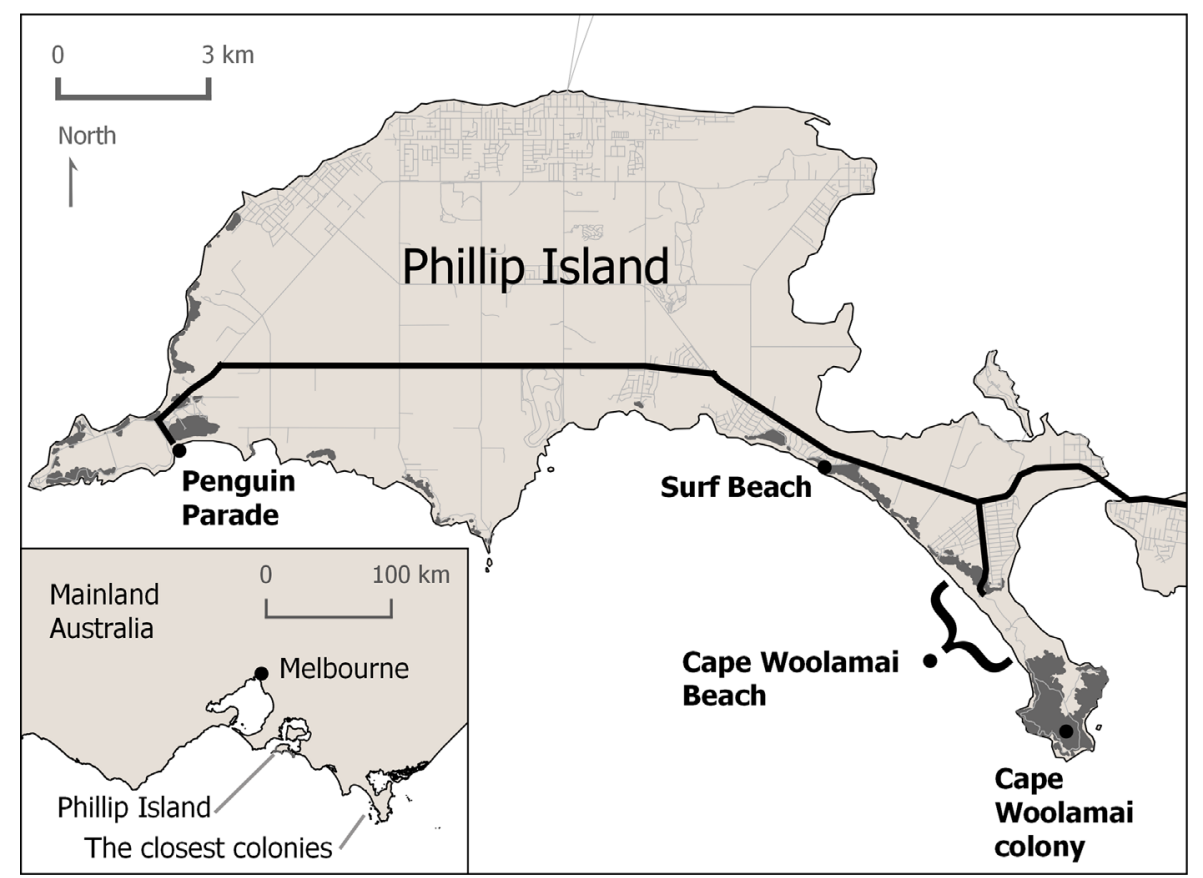

Figure 1. Phillip Island, Victoria, Australia, showing breeding colonies of short-tailed shearwater (dark gray areas) and study locations (black dots), 20142015. The black line represent the roads where rescue patrols looked for grounded birds, which they took to the 2 measurement field stations (Penguin Parade and Surf Beach). The curly bracket represents Cape Woolamai Beach where beach-washed birds were captured. We captured control birds (colony) from the Cape Woolamai colony. The inset is the location of Phillip Island in relation to Melbourne and the closest short-tailed shearwater breeding colonies.

The species uses sand-excavated burrows for nesting along the south coast (Fig. 1) and the largest colony on the island is located at Cape Woolamai with approximately 357,900 pairs (Harris and Bode 1981). There are no other major colonies within $90 \mathrm{~km}$ of Phillip Island.

\section{METHODS}

\section{Sampling Design}

We conducted this study during the 2014 and 2015 fledging periods (from 19 Apr to 5 May). We compared condition and plumage development of shearwaters from 3 locations visited systematically during the fledging period: a colony, a beach, and nearby roads. We visited the Cape Woolamai colony during the 2 hours after sunset looking for fledglings as they emerged from their burrows. We captured birds by hand, measured them, and released them at the capture location. The process for each individual lasted $<5$ minutes and we measured $\leq 20$ individuals/night. At sunrise we visited Cape Woolamai Beach (Fig. 1), looking for beach-washed birds. We placed grounded birds in plastic animal transport boxes and kept them for up to 2 hours until they were dry. After that, we measured and weighed birds then released them into empty burrows at the closest colonies. Since 1996, rescue patrols have been conducted on the island to minimize lightinduced mortality of fledglings during the shearwater fledging period twice a night, once after sunset and once before sunrise. Rescue patrols recover grounded birds, thereby reducing road kills or predation. At least 2 park rangers surveyed the main roads collecting dead and rescuing live birds (Rodríguez et al. 2014). Rangers collected birds grounded on the road by lights, placed them in plastic animal transport boxes, and brought them to 1 of 2 field stations for measuring by authors (Fig. 1). We then released birds into the closest colony. Unfortunately, around 39\% of birds collected on roads were mortally injured or found dead (Rodríguez et al. 2014). We froze dead birds and measured a subsample of undamaged intact bodies. Although, we are confident that the majority of birds included in this category reached roads by flying (distances from colonies to roads is too large or the urban matrix would impede this travel), in some areas some birds could have reached the roads by walking from nesting colonies. We conducted this study under research permit 10007171 issued by the Department of Environment and Primary Industries, Victorian State Government, Australia. The Animal Ethics Committee of Phillip Island Nature Parks approved the procedures under approval number 2.2013.

We recorded date, location (i.e., colony, beach, road), body mass, wing length, bill length (from the base of forehead feathers in the center of their nasal tube to distal extent of the hooked bill), and bill depth (from of base of forehead feathers to ventral surface of lower mandible) for every captured bird. We recorded biometrics using a spring balance (nearest $5 \mathrm{~g}$ ), a ruler (nearest $1 \mathrm{~mm}$ ), and an electronic caliper (nearest $0.01 \mathrm{~mm}$ ). We rated the plumage development according to the presence of down on the head, belly, and back in an ordinal scale $(0=$ absent, $1=$ partially covered, and $2=$ wholly covered by down), and used the sum of the 3 values (head, belly, and back) as an index of down cover, ranging from 0 (down absent) to 6 (head, belly, and back wholly covered by down). Although the number of adults in colonies 
decreases substantially at the end of the breeding season (Skira 1991), we determined which birds were fledglings according to presence of down or unworn plumage. We also recorded the status of birds (dead or alive) collected at the beach or on roads. We marked all live birds individually with permanent marker pen at the toe webbing to identify recaptured individuals. We recaptured 2 birds on the beach and did not include the recapture events in the analyses.

\section{Statistical Analyses}

We investigated 3 response variables: body mass, body condition, and status (live or dead) of road-recovered birds. We used a linear model to test potential differences in the body mass of birds captured in the 3 locations (a factor with 3 levels: beach, colony, and road). We then applied a principal component analysis (PCA) to centered and scaled morphometric variables (wing length, bill length, and bill depth). Morphometric variables showed positive factor loadings (factor loadings: $0.58,0.50$, and 0.64 , respectively) and were positively correlated to the first principal component (Pearson correlation coefficients: $0.74,0.64$, and 0.81 , respectively). The first principal component retained 53\% of variation; we used it as a body size index (BSI) because it was a more realistic indicator of size than single morphometric variables. We calculated a body condition index (BCI) as the standardized residuals of an ordinary least square regression of body mass on BSI, where positive and negative values indicate that birds are heavier and lighter than the average in the population, respectively (Rodríguez et al. 2012). This regression showed a $R^{2}=0.46$ and an $\mathrm{AIC}_{c}$ value 430 units lower than the null model comprising only the intercept (regression model $\mathrm{AIC}_{c}=8,501.8$; null model $\left.\mathrm{AIC}_{c}=8,932.4\right)$. Next, we used linear models to assess how BCI (response variable) varied by date of capture $(1=19$ Apr, $17=5$ May) and the index of down (continuous covariates). We also included location as a 3-level factor predicting $\mathrm{BCI}$ and all potential 2-way interactions (date $\times$ location, date $\times$ down index, and down index $\times$ location). Finally, using only birds collected on the road during rescue patrols, we ran generalized linear models with binomial error distributions to test if status (live $=1$, dead $=0$ ) was correlated to the body condition and down cover of fledglings. We also included the interaction body condition $\times$ down index. We used the complementary log$\log$ (cloglog) link function given our unbalanced dataset (286 live and 56 dead birds; Zuur et al. 2009). We conducted statistical analyses using only data for 2015. Sample size of birds captured in 2014 was too small to be included due to low breeding success (Peter and Dooley 2014), although for a comparison, we report mean and standard deviation of body mass of birds captured in 2014.

We identified the best possible models as models within 5 corrected Akaike's Information Criterion $\left(\mathrm{AIC}_{c}\right.$ ) units from the best model (Burnham and Anderson 2002). We used the candidate models in the final selection, and their weight of evidence $\left(w_{i}\right)$ to estimate averaged regression coefficients. We used full model-averaged coefficients (i.e., coefficients of predictors excluded from candidate models set to 0 ). We ranked all explanatory variables by importance by summing the weights of competing models containing the variable. Thus, a value of 1 indicates the variable was contained in all competing models, and consequently, the highest importance. For the final linear models, we checked the assumptions of normally distributed and homogeneous residuals by inspecting qqplots, scatterplots of residuals plotted against fitted values, and plots of residuals against leverage (Zuur et al. 2009). These plots did not indicate any obvious deviations from these assumptions. For the generalized linear model with binomial error distribution, we assessed Hosmer-Lemeshow goodness-of-fit tests by splitting observations into 3-20 groups. These tests did not show evidence of poor fit (all $P$-values $>0.29$ ). We also calculated the area under the curve (AUC), which is an index of accuracy ranging between 0.5 and 1 . The higher AUC
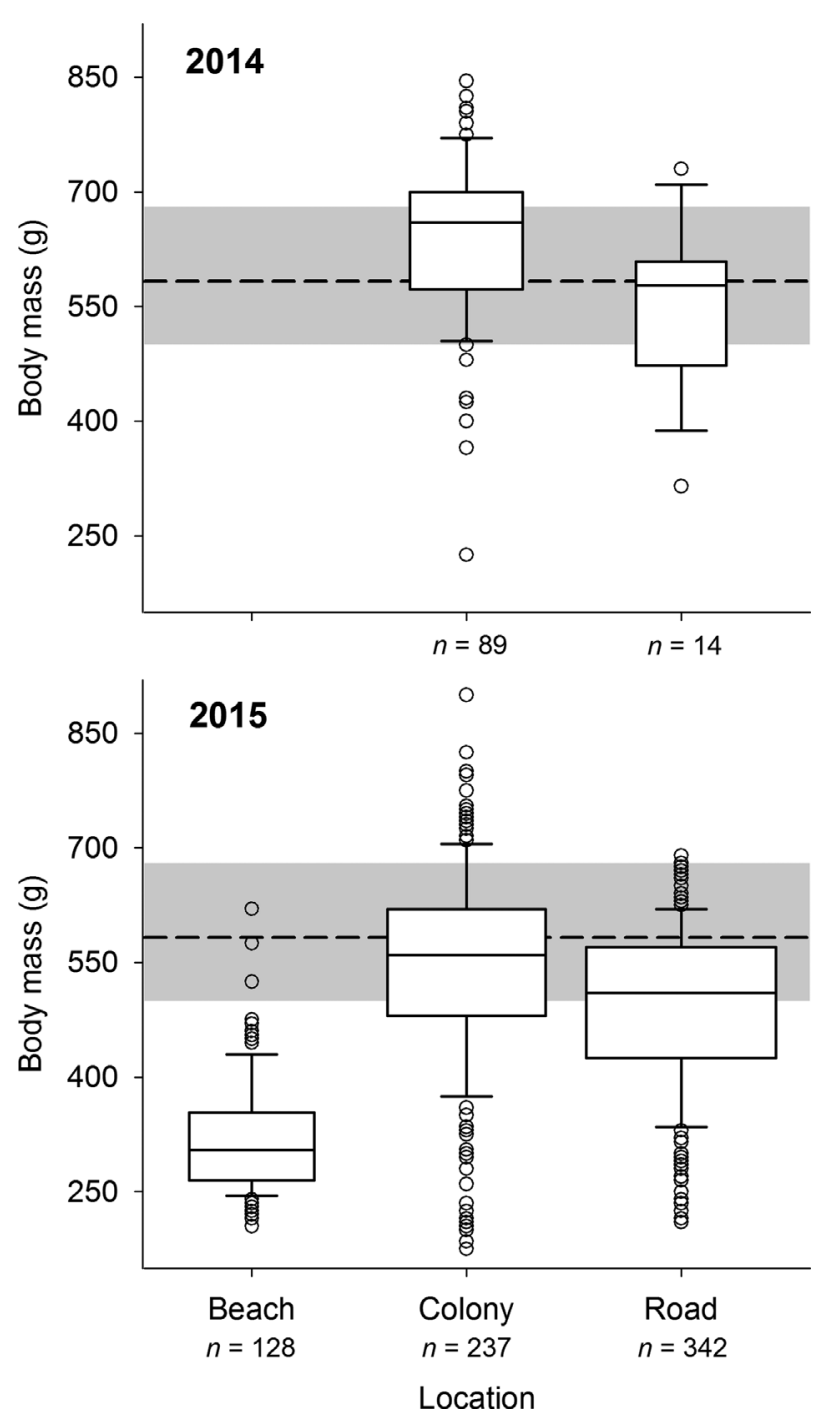

Figure 2. Boxplots of body mass of short-tailed shearwater fledglings captured at 3 locations (beach, colony, and road) on Phillip Island, Australia, 2014-2015. Gray areas indicate the range (500-680 g) and the dashed horizontal lines indicate the mean $(583 \mathrm{~g})$ of adult body masses just before leaving the colony for the non-breeding season according to Lill and Baldwin (1983). 
Table 1. Model-averaged coefficients for analyses of short-tailed shearwater fledglings in 3 locations on Phillip Island, Australia, 2015: fledglings still at the colony, fledglings recovered on roads, and beach-washed fledglings. We conducted 3 analyses: the body mass among locations, the body condition index variation, and the probability of being found alive after being grounded on the road by artificial lights. For each response variable (i.e., body mass, body condition index, and status), we present the predictor variables that appeared in supported models, variable importance (sum of weight of evidence), averaged coefficient estimates, and confidence intervals (95\% CI). For the location factor, beach was our reference level.

\begin{tabular}{|c|c|c|c|c|c|}
\hline Response, predictors & Importance & Averaged estimate & SE & Lower CI (2.5\%) & Upper CI (97.5\%) \\
\hline \multicolumn{6}{|l|}{ Body mass } \\
\hline Intercept & & 322.656 & 9.628 & 303.752 & 341.560 \\
\hline Location (colony) & 1.0 & 223.972 & 11.949 & 200.513 & 247.432 \\
\hline Location (road) & 1.0 & 170.244 & 11.287 & 148.083 & 192.405 \\
\hline \multicolumn{6}{|l|}{ Body condition index } \\
\hline Intercept & & -1.387 & 0.287 & -1.951 & -0.823 \\
\hline Date & 1.0 & 0.079 & 0.031 & 0.018 & 0.141 \\
\hline Down index & 1.0 & 0.096 & 0.120 & -0.140 & 0.332 \\
\hline Location (colony) & 1.0 & 2.129 & 0.322 & 1.496 & 2.761 \\
\hline Location (road) & 1.0 & 0.649 & 0.316 & 0.028 & 1.269 \\
\hline Date $\times$ down index & 1.0 & -0.012 & 0.004 & -0.021 & -0.004 \\
\hline Date $\times$ location (colony) & 1.0 & -0.107 & 0.034 & -0.173 & -0.041 \\
\hline Date $\times$ location $($ road $)$ & 1.0 & 0.001 & 0.033 & -0.064 & 0.066 \\
\hline Down index $\times$ location (colony) & 0.5 & -0.101 & 0.123 & -0.399 & -0.003 \\
\hline Down index $\times$ location (road) & 0.5 & -0.083 & 0.109 & -0.363 & 0.033 \\
\hline \multicolumn{6}{|l|}{ Status $($ dead $=0$, live $=1)$} \\
\hline Intercept & & 0.446 & 0.086 & 0.276 & 0.616 \\
\hline Down index & 1.0 & 0.141 & 0.052 & 0.039 & 0.243 \\
\hline Body condition index & 1.0 & 0.285 & 0.095 & 0.097 & 0.473 \\
\hline Down index $x$ body condition index & 0.5 & -0.038 & 0.057 & -0.197 & 0.031 \\
\hline
\end{tabular}

indicates better prediction power. We conducted statistical analyses in $\mathrm{R}$ (v. 3.3.2, R Core Team 2016) using the MuMIn, ResourceSelection, and pROC packages (Robin et al. 2011, Bartoń 2013, Lele et al. 2014).

\section{RESULTS}

In 2014, we captured 103 birds: 89 at the colony with a mean body mass of $638 \mathrm{~g} \pm 108$ (SD) and 14 on the roads with a mean body mass of $556 \mathrm{~g} \pm 105$ (Fig. 2). We did not collect live birds from the beach in 2014. In 2015, we captured 707 birds: 237 from the colony, 128 on the beach, and 342 on the roads. Dead birds were found in abundance on the beach and roads, but they were often partially eaten by Pacific (Larus pacificus) and silver (Chroicocephalus novaehollandiae) gulls, whistling kites (Haliastur sphenurus), or crushed by cars. The 2015 totals included 2 dead beach-washed and 56 road-killed birds that were found as a whole carcass (i.e., not partially eaten nor damaged by cars). The body mass of birds collected in 2015 differed among locations (Tables 1 and 2), with birds captured at the colony being the heaviest and beach-washed birds being the lightest (colony $=547 \mathrm{~g} \pm 129$; $\operatorname{road}=$ $493 \mathrm{~g} \pm 105$; beach $=323 \mathrm{~g} \pm 76$; Fig. 2).

The best 2 models explaining the body condition of birds explained $23 \%$ of the variance and both included 2 interactions (date $\times$ down index and date $\times$ location; Tables 1 and 2). Body condition decreased with the capture date at the colony, but it increased with date for the birds rescued on the roads and on the beach (Fig. 3). Body condition was also dependent on the interaction between date and down index; the highest values of body condition were reached at the end of the fledging season in birds showing no, or little, down (Fig. 3).

The best model explaining the status (dead or alive) of birds collected on the road during the rescue patrols in relation to

Table 2. Best candidate models for analyses of short-tailed shearwater fledglings in 3 locations on Phillip Island, Australia, 2015: fledglings still at the colony, fledglings recovered on roads, and beach-washed fledglings. We conducted 3 analyses: the body mass among locations, the body condition index variation, and the probability of being found alive after being grounded on the road by artificial lights (status). For each response variable, we present corrected Akaike's Information Criterion $\left(\mathrm{AIC}_{c}\right)$ values for the supported models $\left(<5 \Delta \mathrm{AIC}_{c}\right)$ and the null. We also present log likelihoods $(\log \mathrm{Lik})$ and model weights $\left(w_{i}\right)$.

\begin{tabular}{|c|c|c|c|c|c|c|}
\hline Response & Models & df & $\operatorname{logLik}$ & $\mathrm{AIC}_{c}$ & $\Delta \mathrm{AIC}_{c}$ & $w_{i}$ \\
\hline \multicolumn{7}{|c|}{ Body mass } \\
\hline & Location & 4 & $-4,318.04$ & $8,644.10$ & 0.00 & 1.00 \\
\hline & Intercept (null) & 2 & $-4,464.21$ & $8,932.40$ & 288.30 & 0.00 \\
\hline \multicolumn{7}{|c|}{ Body condition index } \\
\hline & Date + down index + location + date $\times$ down index + date $\times$ location + down index $\times$ location & 11 & -905.47 & $1,833.32$ & 0.00 & 0.50 \\
\hline & Date + down index + location + date $\times$ down index + date $\times$ location & 9 & -907.54 & $1,833.33$ & 0.01 & 0.50 \\
\hline & Intercept (null) & 2 & $-1,003.13$ & $2,010.27$ & 176.96 & 0.00 \\
\hline \multicolumn{7}{|c|}{ Status (live or dead) } \\
\hline & Down index + body condition index & 3 & -144.14 & 294.36 & 0.00 & 0.55 \\
\hline & Down index + body condition index + down index $x$ body condition index & 4 & -143.31 & 294.73 & 0.38 & 0.45 \\
\hline & Intercept (null) & 1 & -152.47 & 306.96 & 12.60 & 0.00 \\
\hline
\end{tabular}




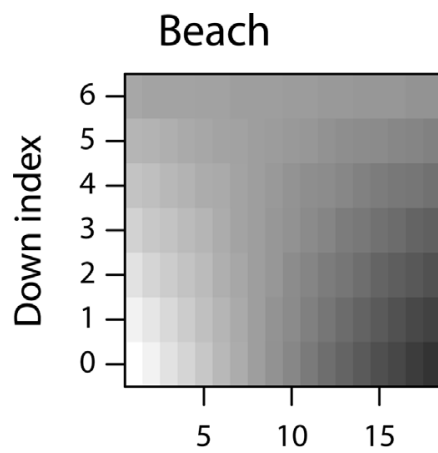

Colony

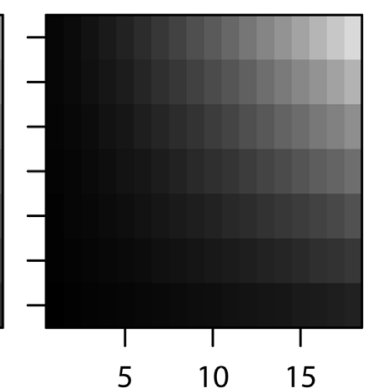

Date (1=19 Apr; 17 = 5 May)
Road

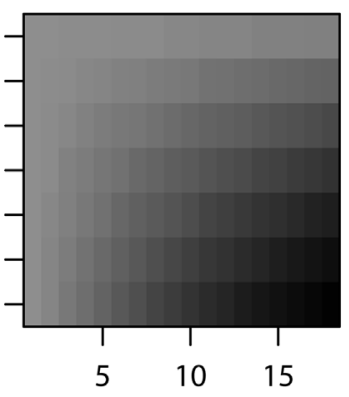

Body condition

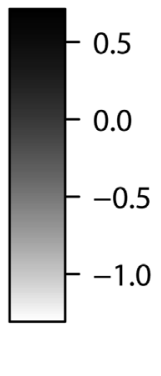

Figure 3. Contour plots displaying the variation of the body condition of short-tailed shearwater fledglings in relation to down index and date at the 3 locations (beach, colony, and road), Phillip Island, Australia, 2015. White and black colors indicate low and high body condition index values, respectively. Down index ranged from 0 (absence of down) to 6 (head, belly, and back completely covered by down).

body condition and down index included simple terms (Tables 1 and 2). The probability of being alive was positively correlated with body condition and down index (Table 1). Birds with better body condition and more down cover had a greater likelihood of being alive at the time of the road rescue patrols (Fig. 4). However, the model had low predictive power $(\mathrm{AUC}=0.67 ; 95 \% \mathrm{CI}=0.59-0.75)$, and it only explained $5.5 \%$ of the deviance.

\section{DISCUSSION}

Understanding which birds have the highest survival probabilities when they are grounded by artificial lights or washed-out onto beaches provides insight into the impacts of light pollution and plumage waterproofing capacities, and allows us to improve the design of rescue programs. We compared, for the first time, the body condition and plumage status of short-tailed shearwater fledglings collected during the rescue of beach-washed and road-grounded fledglings relative to fledglings that were close to departing from the natal colony. Colony birds were the heaviest, followed by birds rescued on roads, and finally by much lighter beachwashed birds. Although the effect size was small (Fig. 4), the probability of being killed on the road decreased with body condition; the better the body condition, the higher the probability of being rescued alive.

In our study, mean body mass values for the 3 locations were below mean values reported for adults just before leaving the colony at the end of breeding $(\bar{x}=583 \mathrm{~g})$ and for chicks at departure $(\bar{x}=616 \mathrm{~g}, 6 \%$ heavier than adults; Lill and Baldwin 1983), which may be due to annual variation (note the considerable variation in weights between our 2 study years). More than $50 \%$ of the birds collected at the colony or rescued on the roads attained the range of values reported by Lill and Baldwin (1983) for adults (range $=500$ $680 \mathrm{~g}$ ), whereas fledglings rescued on the beach were considerably lighter (Fig. 2). Most (92\%) beach-washed birds were $<450 \mathrm{~g}$, which is considered a threshold mass for fledging success in this species according to the Animal
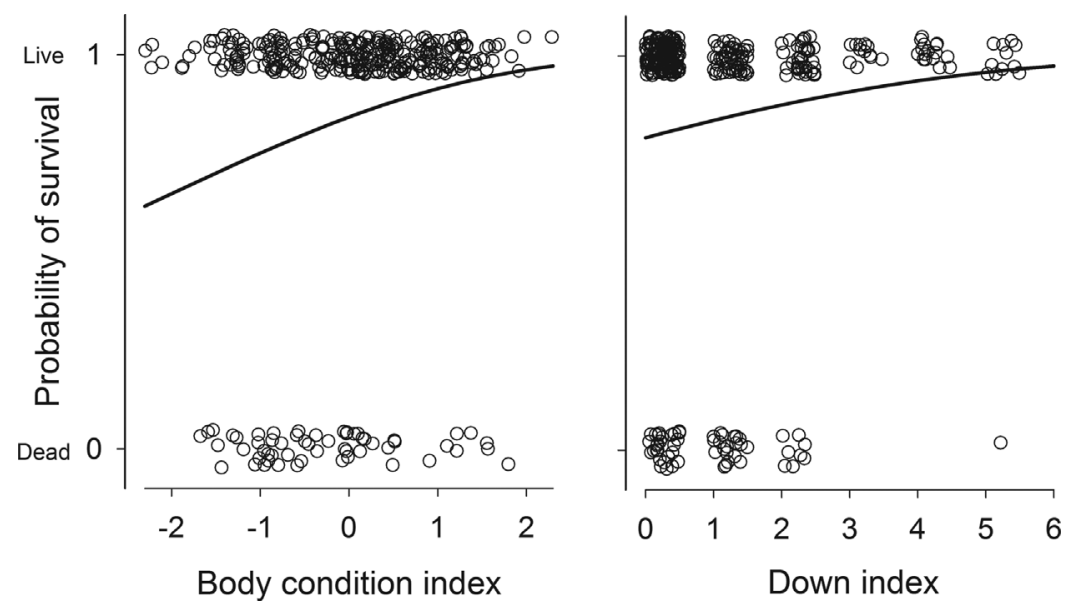

Figure 4. Relationship between probability of being found alive with body condition and down indexes for short-tailed shearwater fledglings, Phillip Island, Australia, 2014-2015. We estimated predicted values using a generalized linear model with a binomial error distribution and complementary log-log link function. Negative and positive values of body condition indicate birds that were below or above the average body mass corrected by body size, respectively. A down index value of 0 means absence of down and 6 means that head, belly, and back were completely covered by down. We jittered points for a better visualization. 
Ethics Committee of Phillip Island Nature Parks. These birds were in a poor body condition prior to fledging and not strong enough to fledge successfully. We observed some birds taking off from tall dunes at colonies toward the ocean, but without enough lift, crashing into the surf. They tried to paddle out beyond the surf without success. They were later washed ashore by waves and currents and frequently predated by Pacific gulls. These birds may have been starving in their burrows and may have fledged prematurely in an attempt to survive. Studies on other species, such as the sooty shearwater or the wedge-tailed shearwater (Ardenna pacifica) also found underweight fledglings involved in similar stranding events at sea and on land (Stonehouse 1964, Work and Rameyer 1999).

Birds rescued on the roads weighed less than birds captured at the colony. This may indicate that grounded birds affected by lights are a subsample of birds in poorer body condition. However, this result could be influenced by our methods; heavier birds sampled at the colony may not have departed on the same night of capture (Perrins et al. 1973). Birds that are fully developed and ready for departure may also be more agile. Thus, our captures at the colony would be biased toward heavier birds that depart later. In an ideal situation, we would sample fledglings at sea on the same day that they fledged, but such sampling was not feasible.

We found that body condition of birds at the colony decreased with date as expected because adults usually cease food provisioning of chicks around 2 weeks before fledging (Serventy 1967 in Skira 1991). In contrast, body condition increased with date for birds grounded on the road or rescued on the beach. Chicks with lower body mass may fledge sooner than chicks with higher body mass because parents may have provisioned or deserted the less heavy chicks earlier. Also, strong winds could facilitate the departure of fledglings that are not fully developed, which would increase the risk of perishing at sea (Skira 1991). Thus, birds in worse body condition may fledge earlier in the fledging season during the first nights with strong winds. Our results contrast with those reported in other studies on light pollution and seabirds. In Cory's, Scopoli's ( $C$. diomedea), and Balearic (Puffinus mauretanicus) shearwaters and Atlantic puffins (Fratercula arctica), fledgling weights declined over time during the rescue period (Rodríguez et al. 2012, 2015a; Wilhelm et al. 2013). This contrast could be explained by different methods between rescue patrols and locations (i.e., rangers actively searching for fledglings on Phillip Island versus opportunistic encounters by lay people in other places around the world). On Tenerife, Canary Islands, where the Cory's shearwater rescue is conducted in collaboration with the general public, global positioning system devices tagged on fledglings identified that some birds were rescued 5 days after being grounded (Rodríguez et al. 2015b). Thus, birds rescued by lay people could experience longer fasting periods, whereas on Phillip Island birds are rescued on the same night they fledge.

The presence of down is inappropriate for the marine phase of the shearwater's life because it increases the water logging capacity of the plumage and hinders flight performance (Ortega-Jiménez et al. 2010). The interaction between date and down cover index is useful in this context to inform best time for rescue. Rescued birds (i.e., fledged ones) with less down in their plumage late in the fledging period were in better condition than birds showing down early in the fledging season, whereas for colony birds the trend was opposite (Fig. 3). Colony birds showing high down cover late in the fledging season showed a poor body condition. Consequently, we propose that, as long as the chick is in good condition, the right time to depart would be late in the season when plumage is fully complete. In contrast, if birds are not in good condition they will fledge early in the fledging season regardless of the down cover in their plumage. Premature fledging may well explain why the body condition increased with date for rescued birds.

\section{MANAGEMENT IMPLICATIONS}

Beach-washed birds were in such poor condition that their survival to recruitment seems improbable. Without intensive care involving feeding and captivity for several days or weeks until birds reach acceptable fledging body condition, rescue of beach-washed birds should be considered as least likely to succeed. Rescue of beach-washed birds would become a priority if the involved species had a dire conservation status (i.e., listed as critically endangered or endangered) in which case every individual may be crucial for its recovery. Birds grounded on roads should be prioritized in rescue programs. Although they showed lower body condition indices and weights than birds at the colony, many had attained values typical of adults so they have a greater chance of survival than beached-washed birds. Because light pollution has an anthropogenic origin, we suggest efforts should be directed toward rescuing birds affected by light pollution and to protect birds at the colonies. Indeed, local authorities could be proactive and implement wildlife-friendly public lighting, which would best mitigate the effects of the fatal attraction of seabirds to artificial lights.

\section{ACKNOWLEDGMENTS}

We are thankful to volunteers and park rangers from the Phillip Island Nature Parks, especially C. R. Cavallo, C. Y. Rogers, C. Miller, D. L. Rogers, E. Jolly, F. R. Chiaradia, G. M. Burgan, J. Skews, K. M. Hollis, K. M. Denny, K. Winn, K. U. Seipp, L. Jones, L. R. Trigg, M. Fischer, M. Cáceres, M. G. G. Lasfargue, N. C. A. Wells, R. Martínez, S. A. Brewin, S. Sánchez, S. A. Robinson, and T. M. Dann. D. G. Ainley and 3 anonymous reviewers improved earlier drafts. This research was supported by a Marie Curie International Outgoing Fellowship within the Seventh European Community Framework Programme (no. 330655 FP7-PEOPLE-2012-IOF). J. M. was a student at the School for International Training Study Abroad Program in Rainforest, Reef, and Cultural Ecology in Australia during this time.

\section{LITERATURE CITED}

Acampora, H., Q. A. Schuyler, K. A. Townsend, and B. D. Hardesty. 2014. Comparing plastic ingestion in juvenile and adult stranded short-tailed 
shearwaters (Puffinus tenuirostris) in eastern Australia. Marine Pollution Bulletin 78:63-68.

Ainley, D. G., R. Podolsky, N. Nur, L. Deforest, and G. A. Spencer. 2001. Status and population trends of the Newell's Shearwater on Kauai: a model for threatened petrels on urbanizad tropical oceanic islands. Studies in Avian Biology 22:108-123.

Bartoń, K. 2013. MuMIn: Multi-model inference, R package, version 1.15.6. http://CRAN.R-project.org/package=MuMIn.

Becker, P. H., and J. S. Bradley. 2007. The role of intrinsic factors for the recruitment process in long-lived birds. Journal of Ornithology 148:377-384.

BirdLife International. 2015. Important Bird Areas factsheet: Phillip Island. http://www.birdlife.org/datazone/sitefactsheet.php?id=23937. Accessed 15 June 2015.

Brooke, M. de L. 2004. Albatrosses and petrels across the world. Oxford University Press, Oxford, United Kingdom.

Burnham, K. P., and D. R. Anderson. 2002. Model selection and multimodel inference: a practical information-theoretic approach. Springer-Verlag, New York, New York, USA.

Carey, M. J. 2011. Intergenerational transfer of plastic debris by short-tailed shearwaters (Ardenna tenuirostris). Emu 11:229-234.

Croxall, J. P., S. H. M. Butchart, B. Lascelles, A. J. Stattersfield, B. Sullivan, A. Symes, and P. Taylor. 2012. Seabird conservation status, threats and priority actions: a global assessment. Bird Conservation International 22:1-34.

Gibson, J. D., and A. R. Sefton. 1955. Mortality of shearwaters. Emu 55:259-262.

Harris, M. P., and K. G. Bode. 1981. Populations of little penguins, shorttailed shearwaters and other seabirds on Phillip Island, Victoria, 1978. Emu 81:20-28.

Le Corre, M., A. Ollivier, S. Ribes, and P. Jouventin. 2002. Light-induced mortality of petrels: a 4-year study from Réunion Island (Indian Ocean). Biological Conservation 105:93-102.

Lele, S. R., J. L. Keim, and P. Solymos. 2014. ResourceSelection: resource selection (probability) functions for use-availability data. $\mathrm{R}$ package version $0.2-4$. https://cran.r-project.org/web/packages/ ResourceSelection/index.html.

Lill, A., and J. Baldwin. 1983. Weight changes and the mode of depot fat accumulation in migratory short-tailed shearwaters. Australian Journal of Zoology 31:891-902.

Maness, T. J., and D. J. Anderson. 2013. Predictors of juvenile survival in birds. Ornithological Monographs 78:1-55.

Meathrel, C. E., and M. J. Carey. 2007. How important are intrinsic factors to natal recruitment in short-tailed shearwaters Puffinus tenuirostris? Journal of Ornithology 148:S385-S393.

Mougin, J.-L., C. Jouanin, F. Roux, and F. Zino. 2000. Fledging weight and juvenile survival of Cory's shearwater Calonectris diomedea on Salvagem Grande. Ringing and Migration 20:107-110.

Ortega-Jiménez, V. M., S. Álvarez-Borrego, S. Arriaga-Ramírez, M. Renner, and E. S. Bridge. 2010. Takeoff flight performance and plumage wettability in Cassin's auklet Ptychoramphus aleuticus, Xantus's murrelet Synthliboramphus hypoleucus and Leach's storm-petrel Oceanodroma leucorhoa. Journal of Ornithology 151:169-177.

Paleczny, M., E. Hammill, V. Karpouzi, and D. Pauly. 2015. Population trend of the world's monitored seabirds, 1950-2010. PLoS ONE 10: e0129342.

Perrins, C. M. 2014. Factors affecting survival of fledgling Manx shearwaters Puffinus puffinus. Seabird 27:62-71.
Perrins, C. M., M. P. Harris, and C. K. Britton. 1973. Survival of Manx shearwaters Puffinus puffinus. Ibis 115:535-548.

Peter, J., and S. Dooley. 2014. The fatal shore: investigating one of the largest seabird wrecks in living memory. Australian Birdlife 3(1):24-27.

R Core Team. 2016. R: a language and environment for statistical computing. R Foundation for Statistical Computing, Vienna, Austria.

Robin, X., N. Turck, A. Hainard, N. Tiberti, F. Lisacek, J.-C. Sanchez, and M. Müller. 2011.pROC: an open-source package for R and $\mathrm{S}+$ to analyze and compare ROC curves. BMC Bioinformatics 12:77.

Rodríguez, A., G. Burgan, P. Dann, R. Jessop, J. J. Negro, and A. Chiaradia. 2014. Fatal attraction of short-tailed shearwaters to artificial lights. PLoS ONE 9:e110114.

Rodríguez, A., D. García, B. Rodríguez, E. Cardona, L. Parpal, and P. Pons. 2015a. Artificial lights and seabirds: is light pollution a threat for the threatened Balearic petrels? Journal of Ornithology 156:893-902.

Rodríguez, A., N. D. Holmes, P. G. Ryan, K.-J. Wilson, L. Faulquier, Y. Murillo, A. F. Raine, J. F. Penniman, V. Neves, B. Rodríguez, J. J. Negro, A. Chiaradia, P. Dann, T. Anderson, B. Metzger, M. Shirai, L. Deppe, J. Wheeler, P. Hodum, C. Gouveia, V. Carmo, G. P. Carreira, L. Delgado-Alburqueque, C. Guerra-Correa, F.-X. Couzi, M. Travers, and M. Le Corre. 2017. A global review of seabird mortality caused by land-based artificial lights. Conservation Biology. doi: 10.1111/cobi.12900

Rodríguez, A., and B. Rodríguez. 2009. Attraction of petrels to artificial lights in the Canary Islands: effect of the moon phase and age class. Ibis 151:299-310.

Rodríguez, A., B. Rodríguez, Á. J. Curbelo, A. Pérez, S. Marrero, and J. J. Negro. 2012. Factors affecting mortality of shearwaters stranded by light pollution. Animal Conservation 15:519-526.

Rodríguez, A., B. Rodríguez, and J. J. Negro. 2015b. GPS tracking for mapping seabird mortality induced by light pollution. Scientific Reports 5:10670

Sagar, P. M., and D. S. Horning. 1998. Mass-related survival of fledgling sooty shearwaters Puffinus griseus at The Snares, New Zealand. Ibis 140:329-331.

Skira, I. 1991. The short-tailed shearwater: a review of its biology. Corella 15:45-52.

Stonehouse, B. 1964. A wreck of juvenile sooty shearwaters. Notornis 11:46-48.

Telfer, T. C., J. L. Sincock, G. V. Byrd, and J. R. Reed. 1987. Attraction of Hawaiian seabirds to lights: conservation efforts and effects of moon phase. Wildlife Society Bulletin 15:406-413.

Warham, J. 1990. The petrels: their ecology and breeding systems. Academic Press, London, United Kingdom.

Warham, J. 1996. The behaviour, population biology and physiology of the petrels. Academic Press, London, United Kingdom.

Wilhelm, S. I., J. J. Schau, E. Schau, M. Suzanne, D. L. Wiseman, H. A. Hogan, and S. M. Dooley. 2013. Atlantic puffins are attracted to coastal communities in Eastern Newfoundland. Northeast Naturalist $20: 624-630$

Work, T. M., and R. A. Rameyer. 1999. Mass stranding of wedge-tailed shearwater chicks in Hawaii. Journal of Wildlife Diseases 35:487-495.

Zuur, A. F., E. N. Ieno, N. Walker, A. A. Saveliev, and G. M. Smith. 2009. Mixed effects models and extensions in ecology with R. Springer, New York, New York, USA.

Associate Editor: Frank Thompson III. 